\title{
Effect of Paraquat and Amyloid- $\beta$-Peptide on the Metabolism in Primary Astrocytes Studied by ${ }^{1} \mathrm{H}-\mathrm{NMR}$
}

\author{
Olesen Birgitte Thuesen ${ }^{\mathrm{a}, \mathrm{b}}$, Zhang Wei ${ }^{\mathrm{a}}$, Clausen Jørgen ${ }^{\#, \mathrm{a}}$, Vang Ole and Hansen Poul Erik*,a \\ ${ }^{a}$ Department of Science, Systems and Models, Roskilde University, P.O. Box 260, DK - 4000 Roskilde, Denmark \\ ${ }^{b}$ Unilabs a.s, Nygaardsvej 32, DK-2100 Copenhagen O, Denmark
}

\begin{abstract}
Amyloid $\beta$-peptide $(\mathrm{A} \beta)$ and Paraquat PQ induce oxidative stress in astrocytes by formation of reactive oxygen species (ROS). The present study determines the cellular response to oxidative stress by use of proton nuclear magnetic resonance $\left({ }^{1} \mathrm{H}\right.$-NMR) spectroscopy. The cellular response was studied in cultured primary astrocytes exposed directly to 5 $\mathrm{mM} P Q$ or $40 \mu \mathrm{M} \mathrm{A} \beta(1-40)$ in the NMR tube (directly) or after a pre-incubation with either $60 \mu \mathrm{M}$ PQ for 48 hours, 10 $\mu \mathrm{M} A \beta(25-35)$ or $\mathrm{A} \beta(1-40)$ for 44 hours. The ROS-mediated modifications in the metabolic profile were followed for at least 2 hours in the NMR spectrometer. Pre-incubation with PQ or A $\beta$ demonstrated increases in the end-products of glycolysis such as pyruvate and lactate. In addition, the concentrations of other metabolites, such as alanine, acetate, methionine, choline, glycine and formate were also increased, whereas the level of glutamate was decreased. These ROSmediated alterations in the metabolic profile are most likely due to disturbances of the enzymes of the tricarboxylic acid (TCA) cycle. The direct effect of PQ led to an increase of succinate among other metabolites. The rate of glycolysis was influenced both by the direct addition of $\mathrm{PQ}$ or after pre-incubation with $\mathrm{A} \beta$ which clearly indicates an increased consumption of glucose. Thus, both PQ and A $\beta$-inducible changes of the metabolic profile were detectable by the use of ${ }^{1} \mathrm{H}$ NMR-spectroscopy.
\end{abstract}

Keywords: Spin-echo NMR spectroscopy, oxidative stress, amyloid peptides, MTT, astrocytes, paraquat.

\section{INTRODUCTION}

Oxidative stress is considered as a major aspect of the pathogenesis of a variety of neurodegenerative disorders e.g. Alzheimer's (AD) [1] and Parkinson's diseases (PD) [2]. A pathological feature of $A D$ is the Amyloid $\beta$-peptide $(A \beta)$ aggregation in the core component of brain neuritic plaques, and the appearance of degenerated neurons, activated microglia and reactive astrocytes [3]. Moreover, considerable evidence implicates that elevated oxidative stress is also part of the mechanism of toxicity of $A \beta$ [4-6]. Several studies have shown markers of oxidative stress to be elevated in the brain with $\mathrm{AD}$, such as oxidation of lipids, protein and DNA [for reviews see 5]). In addition, defects in energy metabolism are a consistent features of AD-affected brains [7].

A $\beta$-peptide is heterogeneous containing 39-43 amino acids residues, derived from a transmembrane protein known as amyloid $\beta$-peptide precursor [8]. The two major alloforms of $A \beta$ in the brain, $A \beta(1-42)$ and $A \beta(1-40)$ and the synthetic and truncated form, $A \beta(25-35)$ have all been demonstrated to be neurotoxic to a wide variety of cells [9-11] through a freeradical-dependent oxidative stress mechanism leading to the generation of hydrogen peroxide $\left(\mathrm{H}_{2} \mathrm{O}_{2}\right)[12,13]$, which is the most abundant peroxide generated in the brain [14].

*Address correspondence to this author at the Department of Science, Systems and Models, Roskilde University, P.O. Box 260, DK-4000 Roskilde, Denmark; Tel: +45 46742432; Fax: +45 46743011;

E-mail: poulerik@ruc.dk

"In memory of Professor Jørgen Clausen.
Paraquat (PQ; 1,1'-dimethyl-4,4'-bipyridinium dichloride) is structurally related to the neurotoxin 1-methyl-4phenyl-1,2,3,6-tetrahydropyridine, which causes PD-like symptoms in humans, primates and mice [lately reviewed by 15]. Paraquat is a herbicide and a widely used model compound to induce intracellular reactive oxygen species (ROS). The toxicity of PQ is due to oxygen-derived superoxide radicals formed by the reaction of oxygen with the paraquat pyridinyl radical cations $\left(\mathrm{PQ}^{\bullet+}\right)$ by a variety of cellular enzymes [16-18]. This redox cycling of PQ leads to reduction/oxidation of the herbicide resulting in further production of superoxide. The superoxide anion undergoes dismutations resulting in the generation of additional ROS. ROS are highly reactive to cellular macromolecules leading to oxidative stress.

In contrast to other organs, brain energy metabolism depends almost exclusively on the oxidation of glucose [19, 20]. The glial localization of pyruvate carboxylase, the key anaplerotic enzyme in the brain [21], and glutamine synthetase [22], suggest an important role of the astrocyte in the brain metabolism. Via tricarboxylic acids (TCA) cycle activity, glucose metabolism also leads to the biosynthesis of neurotransmitters such as glutamate, asparate and $\gamma$ aminobutyric acids (lately rewied in Hertz et al. [20]). The metabolic activities of the energy-producing pathways are under a strict coordinated control and involve glycolysis, the TCA cycle, oxidative phosphorylation and the pentose phosphate pathway.

Astrocytes are key players in control of cerebral metabolism as they are known to interact with surrounding neurons by protecting, nourishing and modulating of growth and ex- 
citability and have extensive contacts with blood vessels and neurons [23, 24]. Astrocytes are metabolically coupled to neurons $[25,26]$ and contributes importantly in the protection of neurons against reactive oxygen species e.g $\mathrm{H}_{2} \mathrm{O}_{2}$ [27, 28]. Oxidative stress is known to affect metabolic pathways of astrocytes that are important for the delivery of metabolites to neurons.

High-field proton nuclear magnetic resonance $\left({ }^{1} \mathrm{H}-\mathrm{NMR}\right)$ is a well established analytic tool in the study of the metabolic status of biofluids [29,30] and the metabolism directly in living cells [31, 32]. Indeed, this technique possesses many advantages over alternative analytical methods, since (i) it is virtually non-invasive (ii) it provides instantaneous multi-component information regarding the metabolic profile of biofluids and appropriate tissue or cell cultures, (iii) it allows detection during a time-series. Furthermore, a metabolic profile can be determined, to define the normal metabolic situation and after addition of xenobiotics and possible yield information about the nature of the metabolic compensations. A complicating factor in the use of ${ }^{1} \mathrm{H}-\mathrm{NMR}$ spectroscopy on biological material is the high information level which may complicate the interpretation of the ${ }^{1} \mathrm{H}-\mathrm{NMR}$ spectra. The low sensitivity of the ${ }^{1} \mathrm{H}-\mathrm{NMR}$ technique may to some extent be overcome by the use of high cell density made possible by growing the cells on micro-carriers [32] which has been used in the present study.

In the present study, cultured primary rat brain astrocytes were exposed to either PQ or $\mathrm{A} \beta$, to test the hypothesis that oxidative stress causes transient damage to astrocytes and affects their metabolism. We have used high field ${ }^{1} \mathrm{H}-\mathrm{NMR}$ spectroscopy to assess the ability of the two ROS inducers PQ and $A \beta$ to affect the metabolic profile mediated by intracellular oxidative damage.

\section{EXPERIMENTAL}

\section{Materials}

Phosphate-buffered saline (PBS), was purchased from Gibco/Invitogen. The following chemicals were from SigmaAldrich: L-Glutamine, Gentamycin, Paraquat, Amyloid $\beta$ peptide (1-40), Amyloid $\beta$ peptide (25-35), dibutyl-cyclic AMP (dBcAMP), MTT (3-[4,5-dimethylthiazol-2-yl]-2,5diphenyl tetrazolium bromide) and $\mathrm{D}_{2} \mathrm{O}$. D-(+)-Glucose, $\mathrm{NaHCO}_{3}$ and $\mathrm{N}, \mathrm{N}$-dimethylformamide were purchased from Merck. SDS was from Bio-Rad Laboratories Inc., Fetal calf serum (FCS) from Harlan Sera-Lab Ltd., Crawleydown, UK, micro-carriers Cellon (90-125 $\mu \mathrm{m})$ from Solo Hill Engineering Inc., USA. $5 \mathrm{~mm}$ NMR tubes from Wilmad, U.S.A. 70 $\mu \mathrm{m}$ nylon filter (Falcon cell strainer) from Becton Dickinson. $75 \mathrm{~cm}^{2}$ culture flanks and other cell culturing equipments were from Costar/Corning. All other chemicals were of highest purity available.

\section{Preparation of Primary Astrocyte Cell Culture}

An astroglia (astrocytes) cell culture was established by the methods described elsewhere [33]. In addition, $85 \mathrm{mg}$ Micro-carrier (suspended in $10 \mathrm{ml}$ PBS, pH 7.4 and autoclaved for $15 \mathrm{~min}$ at $121^{\circ} \mathrm{C}$ ) was added to the astrocytes culture on day 8 . To differentiate the astrocytes, $0.28 \mathrm{mM} \mathrm{dBc}-$ cAMP was added to the cultures during the last week of cul- ture [34]. After three weeks in culture, the primary astrocytes were ready for use.

The primary culture where characterized as nearly $100 \%$ astrocytes [33] using anti-GFAP (glial fibrillary acid protein) as an astrocyte marker [35]. A neuronal interference could be excluded since $\mathrm{N}$-acetylaspartate was clearly absent from all the ${ }^{1} \mathrm{H}$-NMR spectra, as $\mathrm{N}$-acetylaspartate is recognized by the singlet of its $\mathrm{N}$-acetyl $\mathrm{CH}_{3}$ at $2.01 \mathrm{ppm}[36,37]$.

\section{Solutions of $A \beta \quad$ 1-40 and $A \beta \quad 25-35$ and Formation of Aggregates}

Aggregated $A \beta(1-40)$ is often more cytotoxic than soluble $A \beta$ and therefore the peptide was treated in the way described by Isobe et al. [38] and by the manufacturer. A $\beta 1-40$ was dissolved in doubly-distilled and sterile water $\left(\mathrm{ddH}_{2} \mathrm{O}\right)$ to a final concentration of $1390 \mu \mathrm{M}$. For maximal biological activity, the solution was further diluted with calcium and magnesium-free PBS to a final concentration of $350 \mu \mathrm{M}$ and was incubated at $37^{\circ} \mathrm{C}$ for at least 6 days and the solution was mixed by pipeting every third day to facilitate formation of large aggregates.

The $\mathrm{A} \beta$ (25-35) fragment was dissolved in $\mathrm{ddH}_{2} \mathrm{O}$ to 1 $\mathrm{mg} / \mathrm{ml}$ and then in PBS to a final concentration of $350 \mu \mathrm{M}$ without further treatment.

\section{Viability Assay}

The in vitro sensitivity of astrocytes to either $\mathrm{A} \beta$ or $\mathrm{PQ}$ was determined using the MTT viability assay. The assay was performed as described previously [33]. Astrocytes were incubated with $A \beta$ (25-35) in the range 5-40 $\mu \mathrm{M}$ for 6-72 hours, whereas the cytotoxicity of PQ was tested in the range 60-500 $\mu \mathrm{M}$ PQ for 0.5-6 hours or 1 to $5 \mathrm{mM}$ for one hour. Astrocytes exposed to $5 \mathrm{mM}$ PQ for 24 hours were used as positive control. All the presented results are means of four separate wells per experiments and the experiments were repeated twice. Values are expressed as \% of controls $($ mean \pm STD).

\section{Preparation of Samples for ${ }^{1} \mathrm{H}$-NMR Spectroscopy}

The astrocytes and micro-carriers produce a cell-matrix, which was harvested as gently as possible using a "rubberpolice-man". After two times of wash with PBS, the sedimented cell-matrix was mixed with $500 \mu \mathrm{l}$ deuteriated medium leading to a final deuterium content of approximately $75 \%$. Deuteriated medium was prepared from freeze-dried cell culture medium without FCS and re-dissolved in an equal amount of $99.9 \% \mathrm{D}_{2} \mathrm{O}$. Finally, the cell-matrix was transferred to a $5 \mathrm{~mm}$ (O.D.) NMR tube. Prior to data acquisition, a careful shimming was needed since the NMR sample contains a matrix of cells and micro-carriers.

\section{${ }^{1}$ H-NMR Spectroscopy}

The ${ }^{1} \mathrm{H}-\mathrm{NMR}$ spectroscopic studies were performed on a VARIAN Unity-Inova $600 \mathrm{MHz}$ spectrometer using a Watergate pulse sequence [39], which includes a Hahn spin echo sequence [40]. The $1 \mathrm{D}{ }^{1} \mathrm{H}-\mathrm{NMR}$ spectra were recorded with a triple resonance gradient probe at a proton frequency of $599.84 \mathrm{MHz}$ at $37{ }^{\circ} \mathrm{C}$, relaxation delay 0.1 second, $90^{\circ}$ pulse width 8 to $9 \mu \mathrm{s}$, spin echo time (tau) $63 \mathrm{~ms}$, spectral width $8000 \mathrm{~Hz}$, acquisition time 2.048 seconds with $32 \mathrm{~K}$ 
data points, 128 to 256 transients. A selective 3-9-19 $180^{\circ}$ refocusing pulse was applied [41]. $1 \mathrm{mM}$ TSP was added after the NMR experiment was finished. All chemical shifts $(\delta)$ were referenced to the TSP- $\mathrm{d}_{4}$ (sodium 3-(trimethylsilyl)$\left[2,2,3,3-{ }^{2} \mathrm{H}_{4}\right]$ propionate) signal set at $\delta=0 \mathrm{ppm}$. The data were collected in an Array mode: every $10 \mathrm{~min}$ for the first two hours, then every $30 \mathrm{~min}$ for the next two hours and finally every hour for the next 4 hours, resulting in a total collection time of 8 hours. However, only some of the spectra are presented here, such as the spectra at 10, 30 min, 1 hour, 2, 3, 4, 5 and finally 6 hours.

The NMR spectra are presented in the following ways: The effects of prooxidant addition (PQ or $A \beta$ ) on the NMR spectrum are either shown as single-spectrograms or as part $\mathrm{D}$ of a bigger figure, whereas the time-series experiments are illustrated in part A-C of the figures, focusing on three regions; 5.0-9.0 ppm (A), 1.4-4.2 ppm (B) and 0.4-0.9 ppm (C). In all figures, the time from addition of fresh deuteriated medium until the addition of the compound (direct addition) or until the start of recording for pre-incubations is given as $\Delta \mathrm{T}$.

\section{${ }^{1}$ H-NMR Sample Assignments}

Resonance assignments in the ${ }^{1} \mathrm{H}$-NMR were done by $i$ ) comparison with literature value of chemical shifts [37, 42, 43], ii) reference spectra recorded in our laboratory and iii) comparison with spectra from the SDBS database http: //riodb01.ibase.aist.go.jp/sdbs/cgi-bin/cre_index.cgi?lang= eng.

For further verification, a small amount of authentic compound when available was added to the ${ }^{1} \mathrm{H}-\mathrm{NMR}$ sample and a reference spectrum was recorded. Furthermore, the spectra were normalized to creatine, as the creatine level very often is found unchanged during neurodegenerative conditions, and may therefore be used as an internal standard $[36,44]$.

The unusual phases of the $\mathrm{Lac}-\mathrm{CH}_{3}(\delta=1.33 \mathrm{ppm})$, Ala$\mathrm{CH}_{3}(\delta=1.47 \mathrm{ppm}), \mathrm{Lac}-\mathrm{CH}(\delta=4.11 \mathrm{ppm})$ resonance are due to a narrow excitation profile of the 3-9-19 selective pulse.

\section{RESULTS}

\section{Cell Culture}

After 21 days of in vitro primary rat astrocytes isolated from cerebellum covered the micro-carrier beads resulting in a cell-micro-carrier matrix that easily could be transferred to the NMR tubes (Fig. 1A). As shown in Fig. (1A), control cells showed the typical morphology features of quiescent astrocytes in culture, being a monolayer of flat and polygonal-shaped cells. In contrast, incubation with $A \beta(25-35)$ at $10 \mu \mathrm{M}$ for 44 hours or $20 \mu \mathrm{M}$ for 22 hours (Fig. 1B and $\mathbf{C}$ ) induced a marked changes resulting in more stellate-shaped, with a spherical and phase bright cell soma and possess two or more processes. Addition of PQ at $500 \mu \mathrm{M}$ for six hours or $60 \mu \mathrm{M}$ for 72 hours to the primary astrocytes did not reveal any detectable changes of the morphology (data not shown).

\section{Viability Assay (MTT)}

The toxicity of $\mathrm{A} \beta(25-35)$ is limited as the cell viability was not changed following exposure to $40 \mu \mathrm{M} \mathrm{A} \beta(25-35)$ up to $72 \mathrm{~h}$ (Fig. 2A). The effect of PQ on the viability of astrocytes was analyzed at $60 \mu \mathrm{M}$ (Fig. 2B) for $0.5,1,3$ and 6 hours and up to $5 \mathrm{mM}$ for 1 hour (Fig. 2C). None of these concentrations or $500 \mu \mathrm{M}$ PQ for up to 6 hours reduced the ability of the astrocytes to convert MTT. Only when astrocytes were treated with $5 \mathrm{mM}$ for 24 hours (Fig. 2C), a strong toxic effect was observed. Thus, neither A $\beta$ nor PQ used in the present NMR experiments affect the survival rate or the mitochondrial activity of the astrocytes per se.

\section{${ }^{1}$ H-NMR Spectroscopy}

To elucidate the contribution from the medium, a spectrum was recorded (Supplementary Fig. 1) and the resonances of the medium are summarized in Supplementary Table 1. The spectrum of astrocytes without addition of either PQ or A $\beta$ (Fig. 3D, denoted as "reference spectrum") demonstrates the contributions from various cellular metabolites. Several metabolites where identified as shown in Table 1. Identification of resonances between 3.20 to $4.11 \mathrm{ppm}$ was complicated in some instances due to the $\mathrm{C}_{\alpha} \mathrm{H}$ proton resonances of e.g. amino acids making this region crowed. The time-dependent spectra showed a minor increase of lactate/threonine (indicated by an arrow pointing up) at $\delta=1.33$ ppm (Fig. 3C), choline at $\delta=3.20 / 3.22$ ppm (Fig. 3B) and a decrease of glucose at $\delta=5.24$ ppm (Fig. 3A). The strong signal at $\delta=3.2 \mathrm{ppm}$ is generally attributed to choline and choline-containing compound i.e. phosphocholine and glycerophosphocholine. The most obvious time-dependent difference in resonance intensity was seen at $1.33 \mathrm{ppm}$ (Figs.
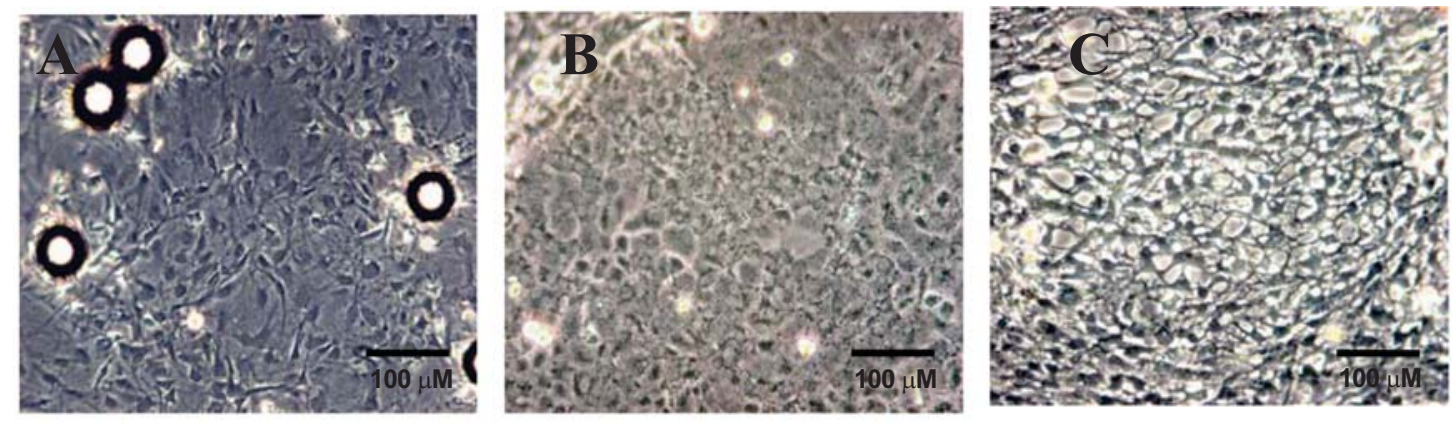

Fig. (1). Morphology of untreated primary astrocytes on micro-carrier beads and after exposure to A $\beta$. After 8 days in vitro, 0.085 mg microcarrier beads were added to the cultures of astrocytes and astrocytes were grown to confluence (additional two weeks). Pictures of astrocytes with micro-carriers were taken under phase contrast. Morphology of $(\mathbf{A})$ untreated astrocytes, $(\mathbf{B})$ astrocytes pre-treated with $10 \mu \mathrm{M} A \beta(25$ 35) for 44 hours or (C) $20 \mu \mathrm{M} \mathrm{A} \beta(25-35)$ for 22 hours. 

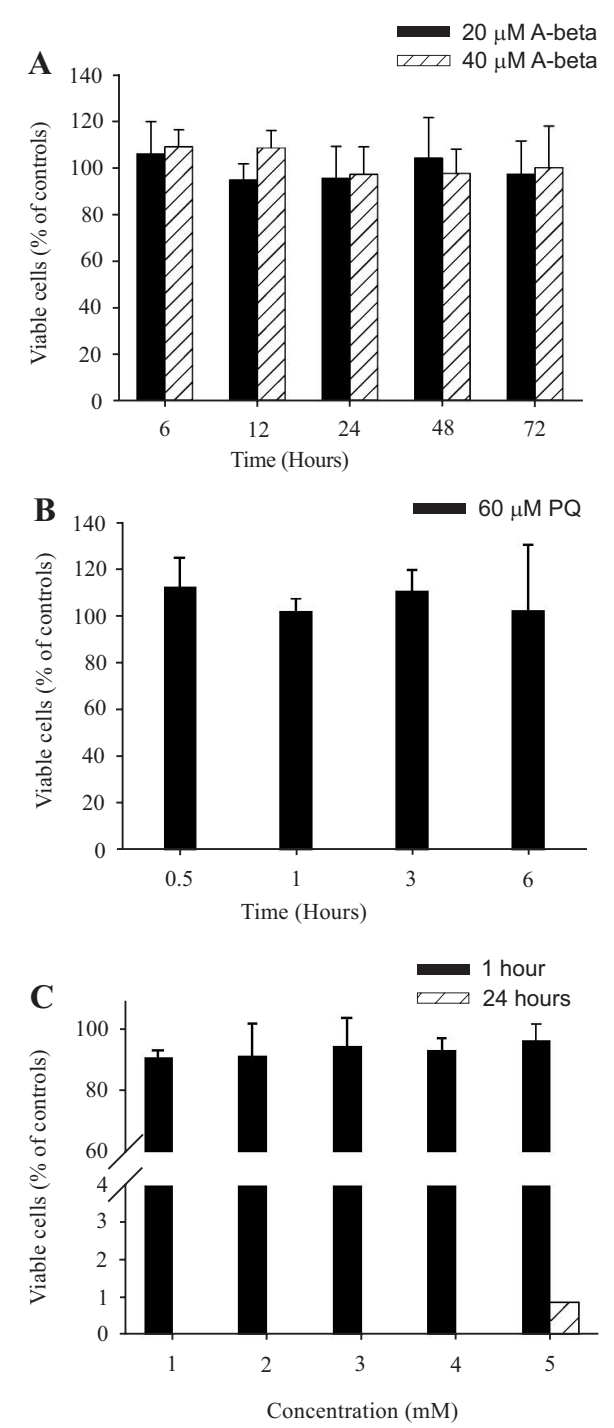

Fig. (2). The viability of astrocytes after exposure to $A \beta(25-35)$ or PQ. Astrocytes were exposed to (A) A $\beta(25-35)(20-40 \mu M)$ for 6 - 72 hours or (B) $60 \mu \mathrm{M}$ PQ for $0.5-6$ hours and the viability was then determined using the MTT assay. In C, the cytotoxic effect of high concentrations of PQ was estimated for 1 or $24 \mathrm{~h}$. Values are expressed as \% of controls (means \pm sd from 4 separate wells). Two independent experiments were performed with similar results but only one experiment is presented here.

Table 1. Assignment of Resonances Belonging to Metabolites in the Reference Spectrum and After Exposure of Astrocytes to PQ or $\mathbf{A} \boldsymbol{\beta}$

\begin{tabular}{|c|c|c|c|}
\hline Metabolite & Proton(s) & Origins & Chemical Shifts, ppm (Multiplicity) \\
\hline \hline Fatty Acids & $\left(-\mathrm{CH}_{3}\right)$ & A.i.r.s. & $0.94(\mathrm{~s})$ \\
\hline $\begin{array}{c}\text { Valine (Val), Isoleucine (Iso), } \\
\text { Leucine (Leu) }\end{array}$ & $\left(-\mathrm{CH}_{3}\right)$ & $\begin{array}{l}\text { Medium } \\
\text { A.i.r.s. }\end{array}$ & $1.33(\mathrm{~d}) /(\mathrm{d})$ \\
\hline Lactate (Lac) / Threonine (Thr) / Fatty acids & $\begin{array}{l}\left(-\mathrm{CH}_{3}\right) \\
\left(-\mathrm{CH}_{2}-\right)\end{array}$ & A.i.r.s. \\
\hline Alanine (Ala) & $\left(-\mathrm{CH}_{3}\right)$ & A.i.r.s. & $1.47(\mathrm{~d})$ \\
\hline Acetate (Ace) & $\left(-\mathrm{CH}_{3}\right)$ & $1.92(\mathrm{~s})$ \\
\hline Glutamate (Glx) & $\left(-\mathrm{CH}_{2}-\right)$ & $2.05(\mathrm{~m})$ \\
\hline Methionine (Met) & $\left(-\mathrm{CH}_{3}\right)$ & $2.15(\mathrm{~s})$ \\
\hline
\end{tabular}


(Table 1). Contd.....

\begin{tabular}{|c|c|c|c|}
\hline Metabolite & $\operatorname{Proton}(s)$ & Origins & Chemical Shifts, ppm (Multiplicity) \\
\hline Glutamine (Glx) & $\left(-\mathrm{CH}_{2^{-}}\right)$ & & $2.45(\mathrm{~m})$ \\
\hline Pyruvate & $\left(-\mathrm{CH}_{3}\right)$ & New & $2.37(\mathrm{~s})$ \\
\hline Succinate & $\left(-\mathrm{CH}_{2^{-}}\right)$ & New & $2.41(\mathrm{~s})$ \\
\hline Methionine (Met) & $\left(-\mathrm{S}-\mathrm{CH}_{3}\right)$ & & $2.65(\mathrm{t})$ \\
\hline Dimethylamine $^{\mathrm{a}}$ & & New & $2.87(\mathrm{~s})$ \\
\hline Creatine/Phosphocreatine (Cre) & $\left(-\mathrm{N}-\mathrm{CH}_{3}\right)$ & A.i.r.s. & $3.03(\mathrm{~s})$ \\
\hline Choline (Cho) & $\left(-\mathrm{N}-\left(\mathrm{CH}_{3}\right)\right)_{3}$ & A.i.r.s. & $3.20(\mathrm{~s})$ \\
\hline \multirow[t]{3}{*}{ Phosphocholine } & $\left(-\mathrm{N}-\left(\mathrm{CH}_{3}\right)\right)$ & A.i.r.s. & $3.22(\mathrm{~s})$ \\
\hline & $\left(-\mathrm{N}-\mathrm{CH}_{2-}\right)$ & A.i.r.s. & $3.25 / 3.27(\mathrm{t})$ \\
\hline & & A.i.r.s. & $3.47(\mathrm{~s})$ \\
\hline Glycine (Gly) & $(-\mathrm{CH}-)$ & & $3.57(\mathrm{~s})$ \\
\hline Alanine (Ala) & $(-\mathrm{CH}-)$ & & $3.77(q)$ \\
\hline Methionine (Met) & $(-\mathrm{CH}-)$ & & $3.84(\mathrm{t})$ \\
\hline Lactate (Lac) & $(-\mathrm{CH}-)$ & A.i.r.s. $\downarrow$ & $4.11(q)$ \\
\hline Glucose (Glu) & $\mathrm{C} 1 \mathrm{H}$ & From medium & $5.24(\mathrm{~d})$ \\
\hline \multirow[t]{4}{*}{ Guanosine } & & New & $5.81(\mathrm{~d})$ \\
\hline & & New & $5.91(\mathrm{~s})$ \\
\hline & & New & $6.06(d)$ \\
\hline & & New & $6.11(\mathrm{~m})$ \\
\hline Tyrosine (Tyr) & & From medium & $6.88(\mathrm{~d}), 7.18(\mathrm{~d})$ \\
\hline Histidine(His) & & & $7.15(\mathrm{~s})$ \\
\hline Phenylalanine (Phe) & & From medium & $7.31(\mathrm{~d}), 7.44(\mathrm{~d})$ \\
\hline Histidine (His) & & A.i.r.s. & $7.95(\mathrm{~s})$ \\
\hline \multirow[t]{2}{*}{ Xanthine $^{\mathrm{b}}$} & & & $7.98(\mathrm{~s})$ \\
\hline & & New & $8.05(\mathrm{~s})$ \\
\hline \multirow[t]{2}{*}{ Hypoxanthine (Hyp) } & $\mathrm{NH}-\mathrm{C}=\mathrm{N} / \mathrm{O}$ & A.i.r.s. & $8.20(\mathrm{~s}), 8.22(\mathrm{~s})$ \\
\hline & & New & $8.35(\mathrm{~s})$ \\
\hline Formate (For) & $\mathrm{HCOO}^{-}$ & A.i.r.s. & $8.46(\mathrm{~s})$ \\
\hline
\end{tabular}

The proton(s) contributing to the resonance intensity and multiplicities of the resonances are described by s, singlet; d, doublet; dd, doublet of doublets; $t$, triplet; q, quartet; m, multiplet.

-Also in reference spectra (A.i.r.s.) of astroglia, but the intensity of the resonance changes further ${ }^{a}$ tentatively assigned to dimethylamine, ${ }^{b}[45]$.

3C and 3D), which may consist of both lactate from the cells, threonine from the medium, but a contribution from fatty acids cannot be excluded. Several resonances increases over time, including lactate $(\delta=1.33)$ (Fig. 3C) and $(\delta=4.11$ ppm) (Fig. 3C), choline-containing resonances $(\delta=3.20-3.25$ ppm) (Fig. 3B), glycine $(\delta=3.57 \mathrm{ppm})$, histidine $(\delta=7.15$ ppm), xanthine $(\delta=7.98 \mathrm{ppm})$, and hypoxanthine $(\delta=8.20 / 8.22$ ppm) (Fig. 3A).

\section{The Direct Effect on Astrocytes Detected by ${ }^{1} \mathrm{H}-\mathrm{NMR}$ Effect of $P Q$}

The additions of 5 or $10 \mathrm{mM}$ PQ were used to demonstrate the acute effect of ROS by PQ treatment. To ensure a detectable effect of PQ-mediated ROS generation, $5 \mathrm{mM}$ was add to the primary astrocyte culture and the metabolic effect was followed for up to 6 hours (Fig. 4). A similar pattern of resonances was detected when astrocytes were treated directly with $10 \mathrm{mM}$ PQ (see Table 2). The direct addition of PQ resulted in a new resonance at $\delta=2.41 \mathrm{ppm}$, which was assigned to succinate. The resonance increased over time (Fig. 4B) and even faster with addition of $10 \mathrm{mM}$ PQ (spectra not shown). In addition, the resonances assigned to alanine, glutamate, succinate, glycine, and hypoxanthine increased over time (Figs. 4A and 4B). Most pronounced was the increase of the choline-containing resonance at $\delta=3.2 \mathrm{ppm}$ (Fig. 4B). The resonance intensity of lactate did not change up to 2 hours after PQ addition (Fig. 4C) but 


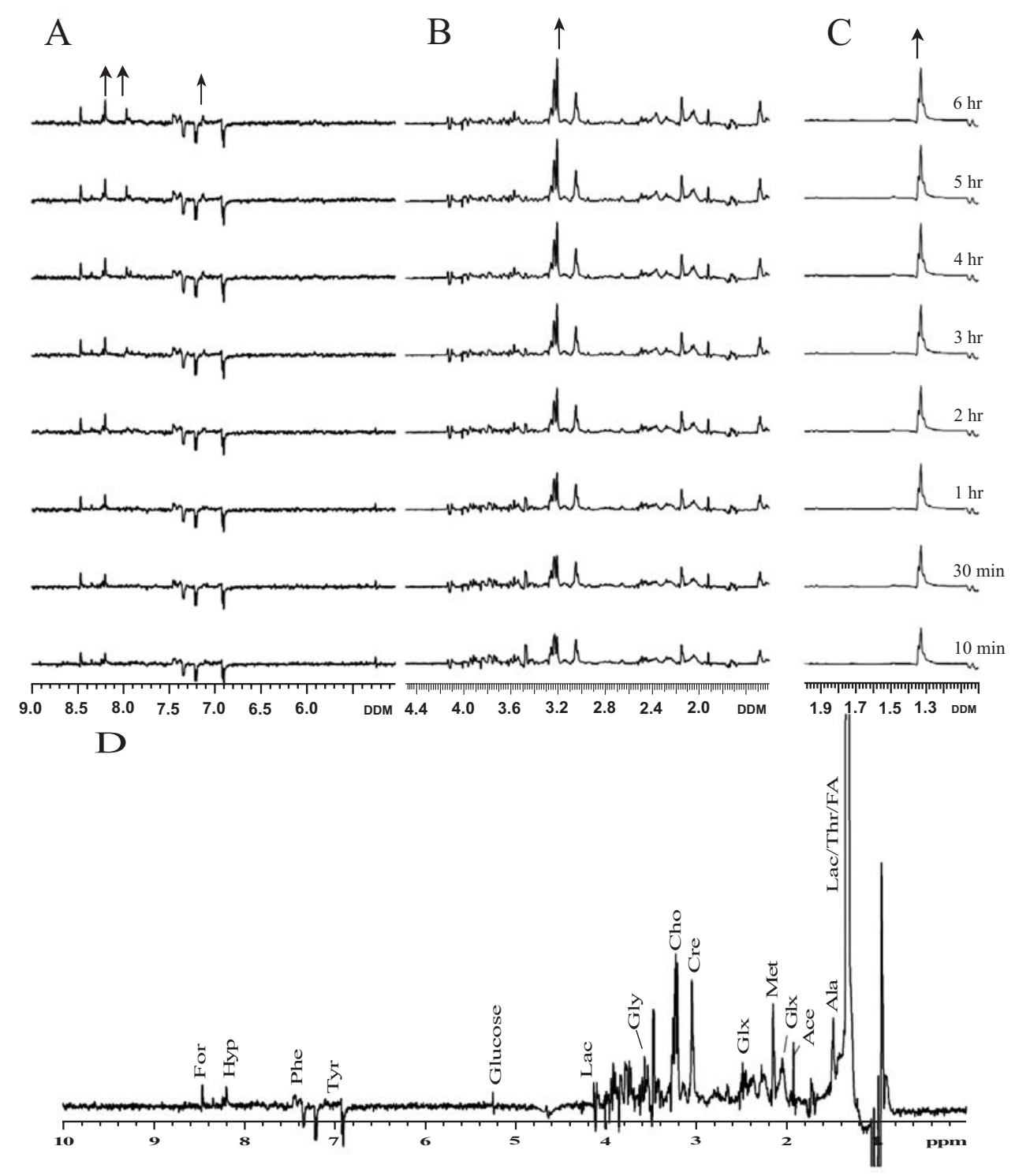

Fig. (3). ${ }^{1} \mathrm{H}$ NMR reference spectra of primary astrocytes in half deuteriated medium. The first spectrum was recorded 34 min after addition of $\mathrm{D}_{2} \mathrm{O}(\Delta \mathrm{T}=34 \mathrm{~min})$ with $10 \mathrm{~min}$ of acquisition; (D). The spectra illustrated in A-C present the different regions. The arrows indicate weather the resonances increases or decreases. The spectra correspond to different measurement times: $+10 \mathrm{~min}, 30 \mathrm{~min}, 1$ hour, $2,3,4,5$ and 6 hours.

subsequently the intensity of the lactate resonance decreased (Fig. 4C). Furthermore, next to the medium resonances from tyrosine (6.88 and $7.18 \mathrm{ppm}$ ), phenylalanine (7.31 and 7.44 ppm) and histidine (7.15 and $7.95 \mathrm{ppm})$, and as time elapsed new resonances appeared at $\delta=7.98,8.05$ and 8.35 as well as a second group of new resonances at $\delta=5.91,6.06$ and 6.11 ppm (Fig. 4A). At a late stage, also resonances at $\delta=7.98$ and $5.81 \mathrm{ppm}$ (guanosine) appeared together with negative resonances at $\delta=7.54$ and $7.73 \mathrm{ppm}$ (trypthophan). Addition of $60 \mu \mathrm{M}$ PQ directly to the NMR-tube was without any detectable difference (spectrum not shown) compared to reference spectrum.

\section{Effect of Amyloid-Beta Peptide}

When $\mathrm{A} \beta(25-35)(10$ or $40 \mu \mathrm{M})$ or $\mathrm{A} \beta(1-40)(10$ or 40 $\mu \mathrm{M})$ were exposed directly to the astrocytes in the NMR tube, no effect was detected for up to 6 hours (spectra not shown). As no acute effect was detected and since the viability test showed no detectable effect for prolonged exposure time, it was relevant to investigate the effect when the astrocytes were pre-incubated with these reagents.

\section{The Effect of Pre-Incubation on Astrocytes Detected by} ${ }^{1}$ H-NMR

In order to control the oxygen level and the environment of the astrocytes for prolonged times, the astrocytes were pre-incubated with either PQ or $\mathrm{A} \beta$ and for up to 48 hours before the astrocytes were investigated by ${ }^{1} \mathrm{H}-\mathrm{NMR}$. Of special interest was the pretreatment with $60 \mu \mathrm{M} P Q$, since this concentration was the subject of a transcriptional characterization in a previous experiment in our laboratory [33]. A long-term effect was found when pre-incubating the astro- 
Table 2. Overview of Changes of Metabolites in Astrocytes Exposed to PQ or A $\beta$ Using ${ }^{1} H$ NMR. These Metabolic Changes Occurs Either Due to Pre-Incubation with PQ or A $\beta$ or During Incubation with PQ or A $\beta$

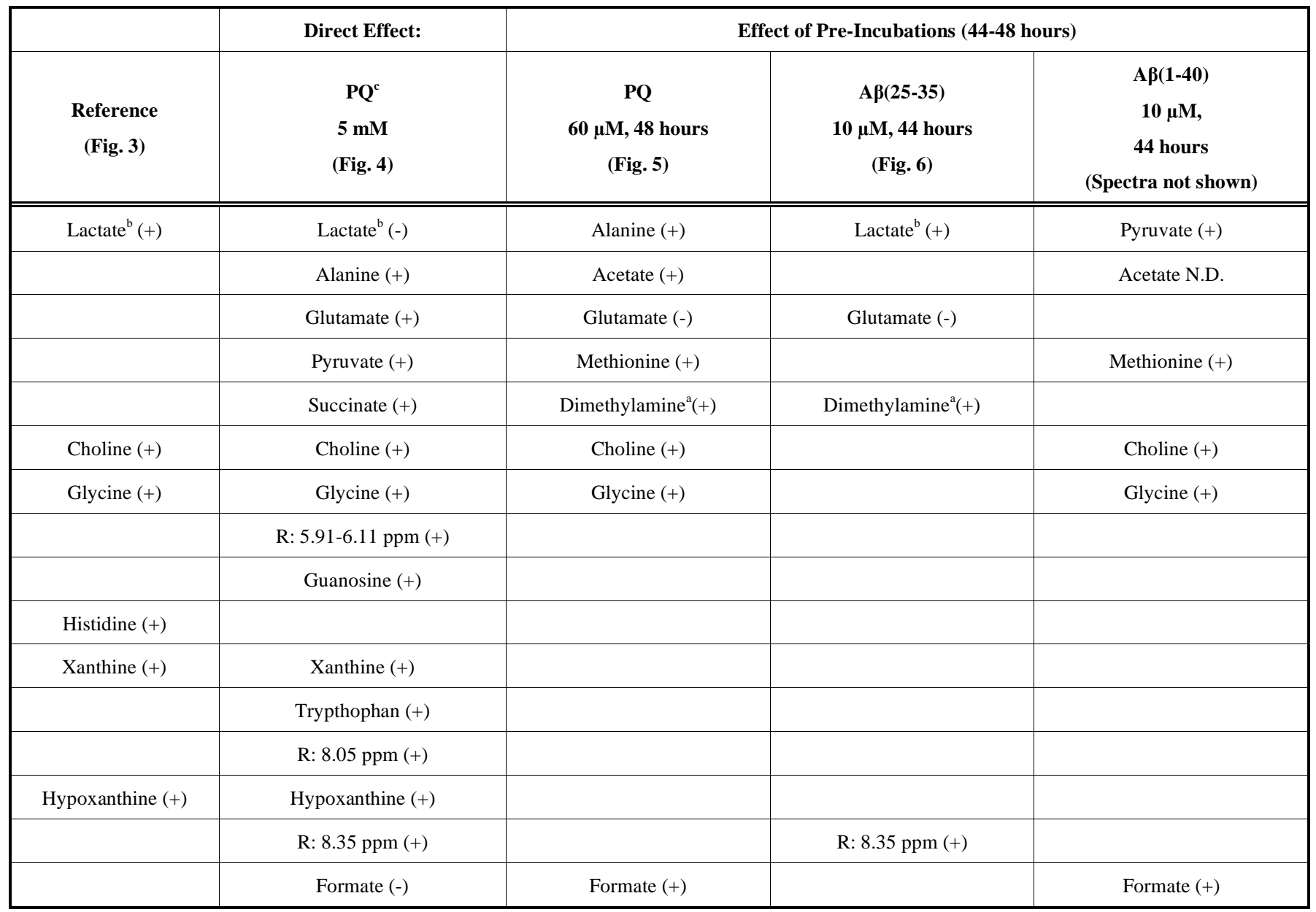

R: resonance, where (-) and (+) indicate resonance decreases and increases, respectively. N.D. not detected. For pre-incubation the increase refers to a comparison with the reference spectrum. For the time-series the spectrum presented in D-panels of the figures is the reference. ${ }^{\mathrm{a}}$ Tentatively assigned to dimethylamine. ${ }^{\mathrm{b}}$ lactate changes are estimated exclusively on the peak intensity at $4.11 \mathrm{ppm}$. ${ }^{\mathrm{c}}$ Succinate increases faster for $10 \mu \mathrm{M}$ PQ (but results are generally similar to $5 \mu \mathrm{M}$ PQ).

cytes with $60 \mu \mathrm{M}$ of PQ for 48 hours (Fig. 5, Table 2). A new resonance at $\delta=2.87 \mathrm{ppm}$, which was tentatively assigned to dimethylamine, and additional new resonances appeared at $\delta=7.15$ and $\delta=7.95 \mathrm{ppm}$, which can be assigned to histidine, were normally only seen in the spectrum of the medium, and neither detectable in the reference spectrum nor after direct addition of $5 \mathrm{mM}$ of PQ (Fig. 4). The long term treatment with PQ also caused a relatively higher resonance intensities of alanine, acetate, methionine, choline, glycine, formate (Fig. 5), whereas glutamate was decreased, compared to the reference spectrum (Fig. 3D). The resonance at $\delta=1.57$ ppm was simply due to the particular medium used in this case.

\section{Effect of Pre-Incubation with Amyloid-Beta Peptide}

Considering the result from the MTT assay, it was appropriate to pre-incubate the astrocytes with $10 \mu \mathrm{M} \mathrm{A} \beta(25$ 35 ) for 22 and 44 hours and $20 \mu \mathrm{M} \mathrm{A} \beta(25-35)$ for 22 hours. The spectra presented here are from an experiment where cells were exposed to $10 \mu \mathrm{M} \mathrm{A} \beta(25-35)$ for 44 hours (Fig. 6). Pre-incubation of astrocytes with $10 \mu \mathrm{M} A \beta(25-35)$ for 44 hours resulted in a new appearance at $\delta=8.35 \mathrm{ppm}$, dimethylamine at $\delta=2.87$ and increase of the resonance inten- sity of lactate, whereas the resonance intensity of glutamate (Glx at $2.05 \mathrm{ppm}$ ) was decreased (Fig. 6) relatively to the reference spectrum (Fig. 3).

To reproduce and to clarify whether the metabolic effect from $A \beta$ was the same whenever the astrocytes were incubated with either the truncated fragment $A \beta(25-35)$ or the full-length $A \beta(1-40)$, astrocytes were pre-incubated with 10 $\mu \mathrm{M} A \beta(1-40)$ for 44 hours (spectra not shown). The preincubations with $A \beta(1-40)$ resulted in an increase of the resonance intensities of pyruvate, methionine, choline, glycine and formate, whereas the resonance of acetate was not detected (Table 2).

\section{DISCUSSION}

In the present study the cellular response after exposure to $\mathrm{PQ}$ or $\mathrm{A} \beta$ on a primary astrocyte cell culture was analyzed using ${ }^{1} \mathrm{H}$-NMR spectroscopy. An important feature of ${ }^{1} \mathrm{H}$ NMR spectroscopy is that it is non-specific, in the sense that signals may be observed without prior specification of which species should be measured. Two problems are important in NMR studies focusing on exposure of xenobiotics to cells in culture, maintenance of physiological conditions and the use of correct doses of the xenobiotics. 


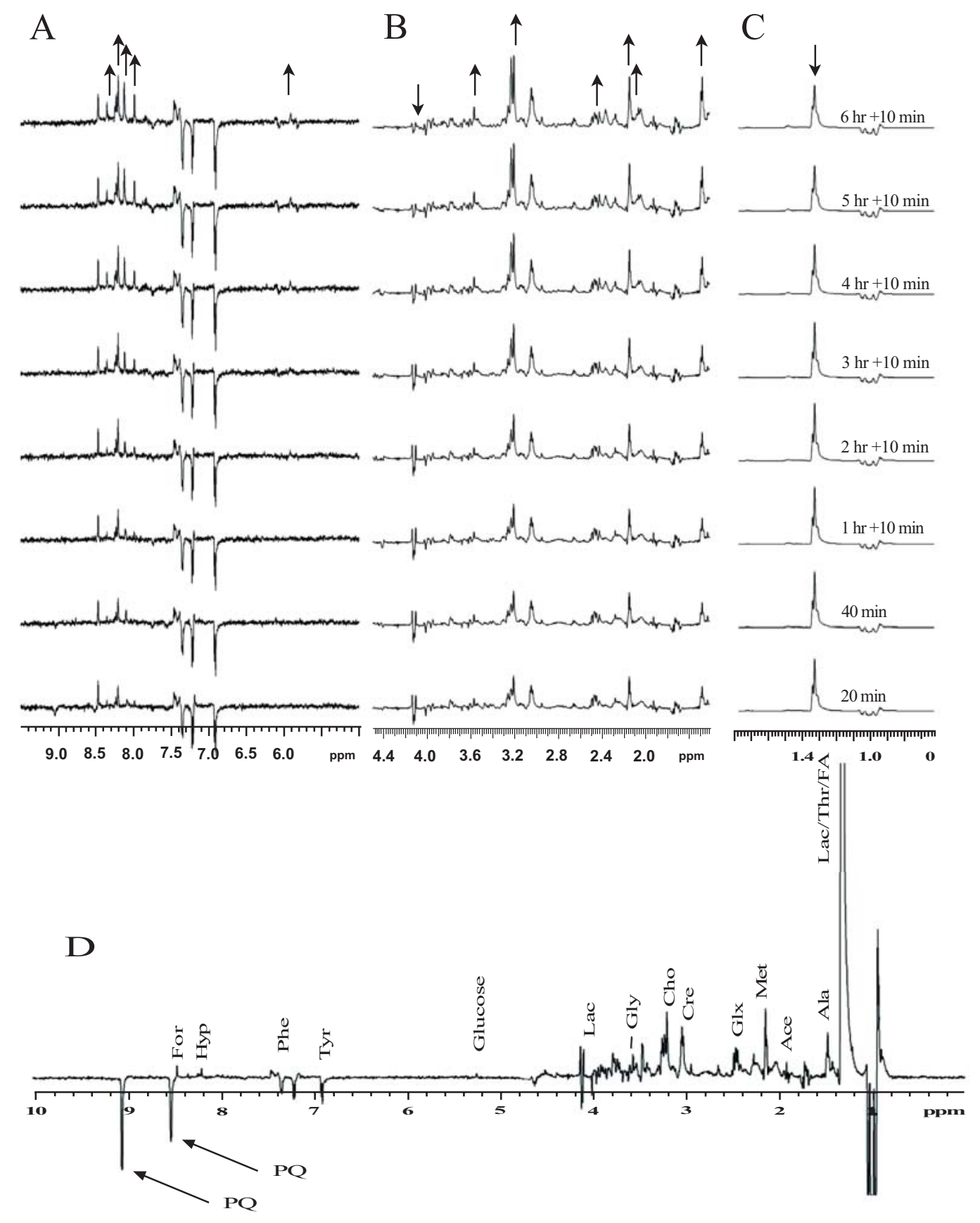

Fig. (4). ${ }^{1} \mathrm{H}-\mathrm{NMR}$ spectra of astrocytes exposed to PQ directly in the NMR-tube. ${ }^{1} \mathrm{H}-\mathrm{NMR}$ spectrum of astrocytes $\Delta \mathrm{T}=53 \mathrm{~min}$ with $\mathrm{D}_{2} \mathrm{O}$ exposed to $5 \mathrm{mM}$ PQ for $10 \mathrm{~min}$ (D). The aromatic protons originating from PQ are clearly visible at 8.58 and $9.11 \mathrm{ppm}$, (see arrows) (D). The metabolic effects of PQ were followed for a total of 6 hours and $10 \mathrm{~min}$. From bottom to top, the spectra correspond to different measurement times as indicated on right side of the lactate resonance of each spectrum, beginning at $20 \mathrm{~min}$. Here $\Delta \mathrm{T}=63 \mathrm{~min}$ for the first spectrum in the time-series, meaning that there is 10 min between $\mathbf{D}$ and the lower panel of $\mathbf{A}, \mathbf{B}$ and $\mathbf{C}$. The arrows indicate weather the resonances increase or decrease.

The experiments presented here are made in different ways: i) addition of compound and the NMR-measurements were started immediately after the addition to investigate the direct effect of the compound followed by a time series ii) pre-incubation with a compound for a relatively long time before the NMR-measurement were initiated. The viability of astrocytes, without addition of ROS generating compounds has previously been shown to be at least 2-3 hours in the NMR-tube [32]. This is further prolonged by the addition of deuteriated medium instead of $\mathrm{PBS} / \mathrm{D}_{2} \mathrm{O}$ under the harvest of astrocytes.

NMR-measurement were conducted for $6 \mathrm{hrs}$ to make changes as obvious as possible, but only the two first hours are discussed in the following. Fresh medium was added just before the NMR-measurement in all cases to the cells and the medium was aerated before transfer of the cells to the 


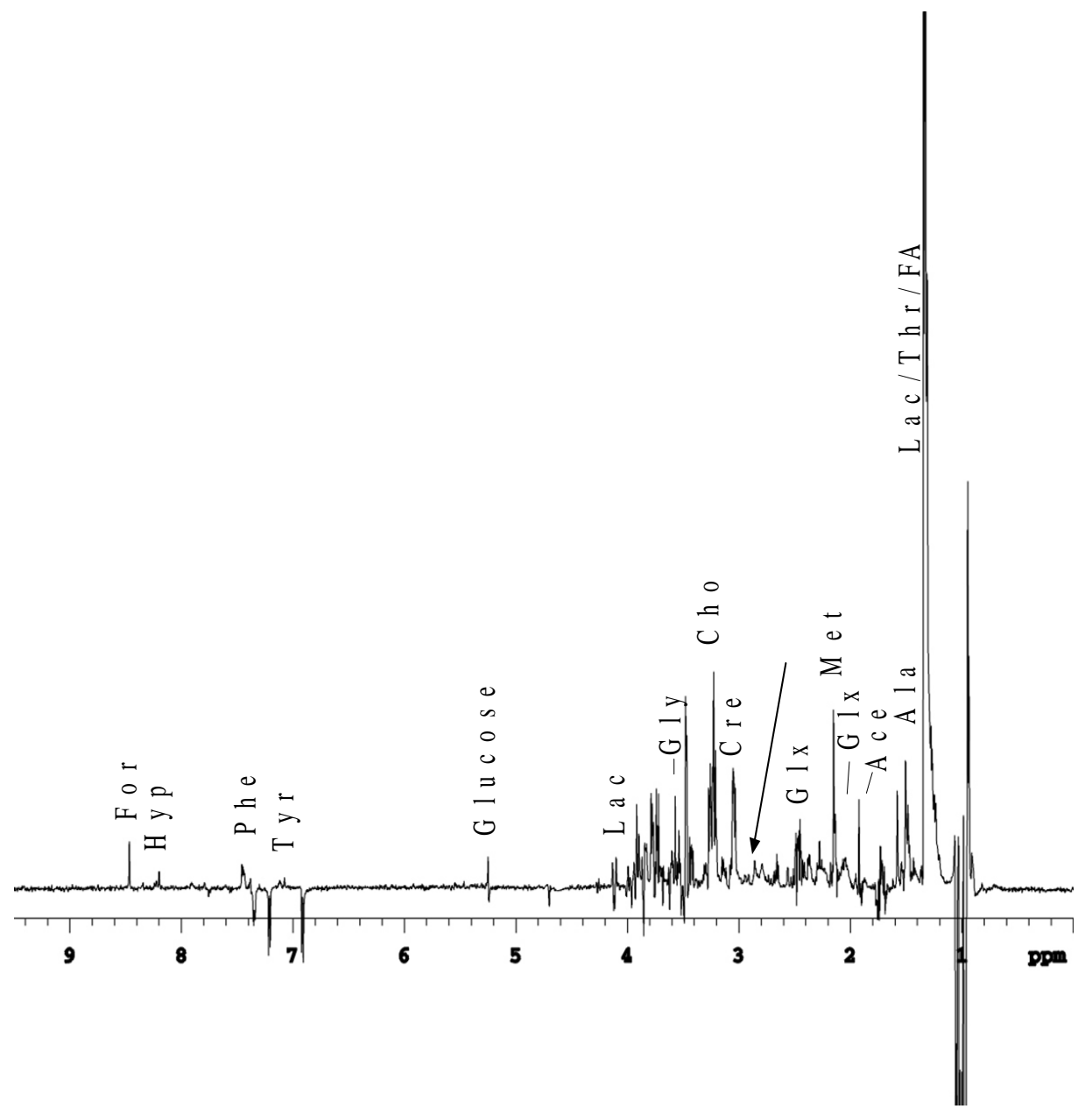

Fig. (5). ${ }^{1} \mathrm{H}-\mathrm{NMR}$ spectra of astrocytes pre-incubated with PQ. The spectrum was recorded at $\Delta \mathrm{T}=48$ min after $\mathrm{D}_{2} \mathrm{O}$ addition and presents the effect after pre-incubation with $60 \mu \mathrm{M}$ PQ for 48 hours. This experiment was performed twice with two independent primary cell cultures with similar results. The arrow indicates the appearance of a new resonance at $2.87 \mathrm{ppm}$.

NMR tube. Two sets of parameters can easily be followed as markers for cell physiology: glucose and lactate on one side and metabolites such as hypoxanthine, choline and histidine on the other (see Table 2). For the cells without additions of PQ or $\mathrm{A} \beta$, the glucose consumption and lactate production is moderate. Glucose is still detectable after 2 hrs despite the fact that the medium used here is only half the concentration of normal media. For 1-2 hours, the development of metabolites is moderate (Fig. 3A-C). At longer times hypoxanthine develops (Table 2 ) indicating possible hypoxia.

The direct addition of $5 \mathrm{mM}$ PQ had no immediate effects except for the consumption of glucose (Fig. 4D). The time series (Fig. 4A-C) showed increased lactate production for up to two hours. Furthermore, PQ $(5 \mathrm{mM})$ seemed to disturb the oxidative metabolism of the mitochondrial tricarboxylic acid (TCA) cycle, indicated by the increase in the metabolites of succinate (new) and glutamate in the timeseries (Fig. 4B) as well as the lost ability to reduce MTT seen in the MTT assay when exposure to $5 \mathrm{mM}$ PQ was extended to 24 hours (Fig. 2C) [46]. Succinate is a component in the TCA cycle, whereas glutamate may enter the TCA cycle via $\alpha$-ketoglutarate. Alternatively, the accumulation of succinate could be a direct consequence of a nonenzymatic decarboxylation of $\alpha$-ketoglutarate observed under oxidative stress [47]. The accumulation of succinate and glutamate may occur through the inhibitions of TCA enzymes $\alpha$ ketoglutarate dehydrogenase $(\alpha-\mathrm{KGDH})$ and succinate dehydrogenase (SDH). $\alpha \mathrm{KGDH}$ and $\mathrm{SDH}$ have been shown to be sensitive to inactivation by increased $\mathrm{H}_{2} \mathrm{O}_{2}$ concentration, both in vivo and in vitro [7, 48, 49]. Thus, the blockage of these TCA enzymes would slower the TCA that would lead to accumulation of pyruvate and in turn to increase of alanine and lactate levels. These alterations are observed to some extent as the resonances of alanine and pyruvate were increased together with a minor increase of lactate.

The MTT assay clearly demonstrated that the selected concentrations of PQ $(60 \mu \mathrm{M})$ [33] and A $\beta(25-35)$ (either 20 or $40 \mu \mathrm{M})$ does not increase the mortality of the astrocytes for up to $72 \mathrm{hrs}$. However, ${ }^{1} \mathrm{H}-\mathrm{NMR}$ showed an effect when astrocytes were pre-incubated with $60 \mu \mathrm{M}$ PQ or $10 \mu \mathrm{M}$ $\mathrm{A} \beta(25-35)$. New resonances such as acetate (only PQ) and a resonance at $\delta=2.87 \mathrm{ppm}$ tentatively assigned to dimethy- 


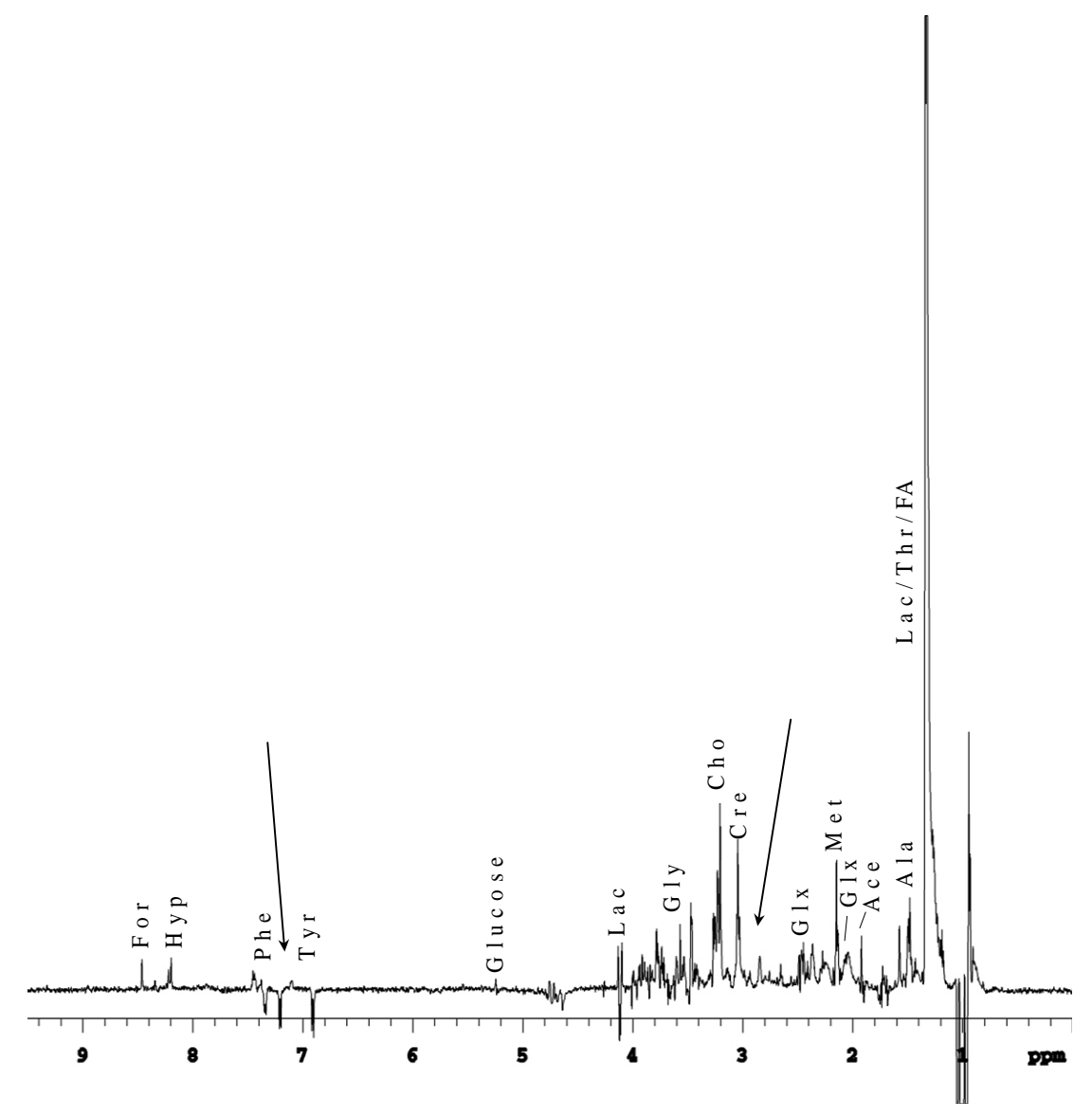

Fig. (6). ${ }^{1} \mathrm{H}$ NMR spectra of primary astrocytes were pre-treated with A $\beta$. Astrocytes were pre-incubated with $10 \mu \mathrm{M} A \beta(25-35)$ for 44 hours. Hereafter the cells were washed twice in phosphate buffered saline (PBS), and transferred in $500 \mu \mathrm{M}$ deuteriated medium to a $5 \mathrm{~mm}$ NMR tube. The spectrum was recorded $\Delta \mathrm{T}=31 \mathrm{~min}$. The arrows indicate the appearance of new resonances at $2.87 \mathrm{ppm}$ and $7.18 \mathrm{ppm}$.

lamine (both $\mathrm{PQ}$ and $\mathrm{A} \beta(25-35)$ ) were observed. In addition, an indication of a disturbed metabolic profile is given by the fact, that various metabolites such as alanine, acetate, pyruvate, dimethylamine, methionine, choline and formate are increased relative to the reference spectrum, while the resonance assigned to glutamate (Glx) at $\delta=2.05 \mathrm{ppm}$ decreased.

Indications of $P Q$ or $A \beta$ induced oxidative stress alteration in the metabolic profile in astrocytes after preincubation can be seen by the increased intensity of acetate $(\mathrm{PQ})$ and formate (PQ and $\mathrm{A} \beta(1-40))$. The increase in acetate is presumably a compensatory effect to protect biomolecules from ROS. Other studies indicate that $\alpha$-keto-acids, such as pyruvate, may act as scavenger molecules [50] leading to the generation of acetate via oxidative decarboxylation. This will also explain why pyruvate is only slightly increased. Moreover, the increased signal of formate may also serve as a "marker" of oxidative damage, due to the oxidative attack of hydroxyl radical $(\bullet \mathrm{OH})$ on carbohydrates in particular (e.g. glucose, glucosaminoglycans) and the molecularly mobile carbohydrate side-chains of glycoproteins in general [51, 52 ]. The reduced glutamate content in astrocytes is probably a consequence of consumption of glutamate as an intermediate in the TCA cycle or used in synthesis of glutathione (GSH). The formation of ROS can lead to depletion of endogenous antioxidants and the TCA is partly inhibited by dogenous antioxidants and the TCA is partly inhibited by ROS. As a consequence synthesis of GSH needs to be enhanced, which will lead to a reduction of the components of GSH, glutamate, cysteine and glycine. No such reduction of glycine was observed either because the GSH recycling is working properly or because ${ }^{1} \mathrm{H}-\mathrm{NMR}$ is not suitable for determination of glycine. A direct measurement of the GSH depletions, as a consequence of its oxidation, cannot be followed due to lack of sensitivity of the ${ }^{1} \mathrm{H}-\mathrm{NMR}$ technique.

In the time series especially the consumption of glucose and the production of lactate were obvious. Lactate is normally characterized by a resonance at $\delta=1.33 \mathrm{ppm}$. However, this signal coincides with those of threonine and fatty acids $[53,54]$. Therefore, the estimations of lactate here is based only on its methine proton at $\delta=4.11 \mathrm{ppm}$. The intensity of this resonance could be influenced by deuterium incorporation. However, this is not the case here, due to the short time span [55]. Increasing lactate level has formerly been considered a marker for ischemia and hypoxia [56] but is now also known as a significant player in brain metabolism and bioenergetics [25, 57]. Evidence for lactate being secreted from astrocytes and preferentially metabolized by neurons has accumulated $[58,59]$ and the concept of a lactate/alanine shuttle between astrocytes and neurons was proposed.Using 
combination of ${ }^{13} \mathrm{C}$-NMR labelled glucose and lactate demonstrates the astrocyte-neuron lactate shuttle in the coupling of between cerebral activity and energy metabolism [25, 60, 61].

A decrease of the glucose signal at $\delta=5.24 \mathrm{ppm}$ indicate glucose consumption. In particular, the direct exposure to 5 $\mathrm{mM} P Q$ or $\mathrm{A} \beta(1-40)(40 \mu \mathrm{M})$ increased glucose consumption resulting in a decrease in resonance intensity of glucose after $63 \mathrm{~min}$ or $59 \mathrm{~min}$, respectively together with the preincubation with $A \beta(25-35)(10 \mu \mathrm{M})$. In contrast, the preincubation with $60 \mu \mathrm{M}$ PQ or $A \beta(1-40)$ did not lead to a significant increase in the consumption of glucose possible due to a shift of the oxidative metabolism from glycolysis and TCA cycle towards the pentose phosphate pathway which is know to be involved in the $\mathrm{H}_{2} \mathrm{O}_{2}$ disposal [14]. In addition, when glucose is not limited, astrocytes has been found to upregulate their capacity to metabolize glucose during hypoxia and during oxidative stress [62], and thereby maintain their energetic status during hypoxia (up to 2 hours) at the expense of increased glucose utilization under anaerobic conditions [63].

\section{CONCLUSION}

In conclusion, high-field ${ }^{1} \mathrm{H}-\mathrm{NMR}$ spectroscopy offers many advantages over alternative time-consuming labour intensive analytic methods and can be used to study the metabolic profile evolving over time. This allows a rapid, virtually non-invasive and instantaneous examination of a very wide range of components present in living astrocytes. The primary astrocytes represent on the other hand a model system wherein the biological effects of xenobiotics can be analyzed in a biological system by the use of ${ }^{1} \mathrm{H}-\mathrm{NMR}$ spectroscopy. The main drawback at the moment is the low sensitivity. This can hopefully in the future be overcome by use of polarization techniques beautifully demonstrated using ${ }^{13}$ C NMR [64].

We could demonstrate oxidative stress-induced metabolic alteration due to $\mathrm{PQ}$ and $\mathrm{A} \beta$ peptide. In particular the resonances from the end-products of glycolysis, lactate and pyruvate, and other metabolites such as alanine, acetate, methionine, choline, glycine and formate increased. Glutamate was decreased as a consequence of pre-incubation. It is also obvious that pre-incubation or addition of a large concentration of PQ increased the metabolic activity considerably.

\section{ABBREVIATIONS}

$$
\begin{array}{ll}
\mathrm{A} \beta & =\text { Amyloid } \beta \text {-peptide } \\
\alpha-\mathrm{KGDH} & =\alpha \text {-ketoglutarate dehydrogenase } \\
\mathrm{ddH}_{2} \mathrm{O} & =\text { doubly-distilled and sterile water } \\
\mathrm{dBcAMP} & =\text { dibutyl-cyclic AMP } \\
\mathrm{FCS} & =\text { Fetal calf serum } \\
\mathrm{GSH} & =\text { Glutathione } \\
\mathrm{MTT} & =3 \text {-[4,5-dimethylthiazol-2-yl]-2,5-diphenyl tetra- } \\
& \text { zolium bromide } \\
\text { PBS } & =\text { Phosphate-buffered saline } \\
\text { PQ } & =\text { Paraquat }
\end{array}
$$

$$
\begin{array}{ll}
\text { ROS } & =\text { Reactive Oxygen Species } \\
\text { SDH } & =\text { Succinate dehydrogenase } \\
\text { TCA } & =\text { tricarboxylic acid } \\
\text { TSP- } \mathrm{d}_{4} & \left.={ }^{2} \mathrm{H}_{4}\right] \text { propionate }
\end{array}
$$

\section{ACKNOWLEDGEMENTS}

We would like to thank the Lundbeck foundation for financial support and Professors N.Viereck and L. Nørgård , KU Life for their kind help.

\section{SUPPLEMENTARY MATERIAL}

Supplementary material is available on the publishers Web site along with the published article.

\section{REFERENCES}

[1] Mamelak M. Alzheimer' s disease, oxidative stress and gammahydroxybutyrate. Neurobiol Aging 2007; 28: 1340-60.

[2] Jenner P. Oxidative stress in Parkinson's disease. Ann Neurol 2003; 53(Suppl 3): S26-S36.

[3] Meda L, Baron P, Scarlato G. Glial activation in Alzheimer's disease: the role of $\mathrm{A}[\mathrm{beta}]$ and its associated proteins. Neurobiol Aging 2001; 22: 885-93.

[4] Varadarajan S, Yatin S, Aksenova M, Butterfield DA. Review: Alzheimer's amyloid beta-peptide-associated free radical oxidative stress and neurotoxicity. J Struct Biol 2000; 130: 184-208.

[5] Butterfield DA, Lauderback CM. Lipid peroxidation and protein oxidation in Alzheimer's disease brain: potential causes and consequences involving amyloid beta-peptide-associated free radical oxidative stress. Free Radic Biol Med 2002; 32: 1050-60.

[6] Milton NG. Role of hydrogen peroxide in the aetiology of Alzheimer's disease: implications for treatment. Drugs Aging 2004; 21 : 81-100.

[7] Gibson GE, Park LC, Sheu KF, Blass JP, Calingasan NY. The alpha-ketoglutarate dehydrogenase complex in neurodegeneration Neurochem Int 2000; 36: 97-112.

[8] Haass C, Selkoe DJ. Cellular processing of [beta]-amyloid precursor protein and the genesis of amyloid [beta]-peptide. Cell 1993; 75: $1039-42$

[9] Butterfield DA. beta-Amyloid-associated free radical oxidative stress and neurotoxicity: Implications for Alzheimer's disease. Chem Res Toxicol 1997; 10: 495-506.

[10] Yatin SM, Aksenova M, Aksenov M, Markesbery WR, Aulick T, Butterfield DA. Temporal relations among amyloid beta-peptideinduced free-radical oxidative stress, neuronal toxicity, and neuronal defensive responses. J Mol Neurosci 1998; 11: 183-97.

[11] Yatin SM, Varadarajan S, Link CD, Butterfield DA. In vitro and in vivo oxidative stress associated with Alzheimer's amyloid $\beta$-peptide (1-42). Neurobiol Aging 1999; 20: 325-30.

[12] Brera B, Serrano A, de Ceballos ML. [beta]-Amyloid peptides are cytotoxic to astrocytes in culture: a role for oxidative stress. Neurobiol Dis 2000; 7: 395-405.

[13] Kaminsky YG, Kosenko EA. Effects of amyloid-beta peptides on hydrogen peroxide-metabolizing enzymes in rat brain in vivo. Free Radic Res 2008; 42: 564-73.

[14] Dringen R, Pawlowski PG, Hirrlinger J. Peroxide detoxification by brain cells. J Neurosci Res 2005; 79: 157-65.

[15] Hald A, Lotharius J. Oxidative stress and inflammation in Parkinson's disease: is there a causal link? Exp Neurol 2005; 193: 279-90.

[16] Bus JS, Aust SD, Gibson JE. Superoxide- and singlet oxygencatalyzed lipid peroxidation as a possible mechanism for paraquat (methyl viologen) toxicity. Biochem Biophys Res Commun 1974; 58: 749-55. 
[17] DeGray JA, Rao DN, Mason RP. Reduction of paraquat and related bipyridylium compounds to free radical metabolites by rat hepatocytes. Arch Biochem Biophys 1991; 289: 145-52.

[18] Tampo Y, Tsukamoto M, Yonaha M. Superoxide production from paraquat evoked by exogenous NADPH in pulmonary endothelial cells. Free Radic Biol Med 1999; 27: 588-95.

[19] Gjedde A, Marrett S. Glycolysis in neurons, not astrocytes, delays oxidative metabolism of human visual cortex during sustained checkerboard stimulation in vivo. J Cereb Blood Flow Metab 2001; 21: 1384-92.

[20] Hertz L, Peng L, Dienel GA. Energy metabolism in astrocytes: high rate of oxidative metabolism and spatiotemporal dependence on glycolysis/glycogenolysis. J Cereb Blood Flow Metab 2007; 27: 219-49.

[21] Shank RP, Bennett GS, Freytag SO, Campbell GL. Pyruvate carboxylase: an astrocyte-specific enzyme implicated in the replenishment of amino acid neurotransmitter pools. Brain Res 1985; 329: 364-67.

[22] Norenberg MD, Martinez-Hernandez A. Fine structural localization of glutamine synthetase in astrocytes of rat brain. Brain Res 1979; 161: 303-10

[23] Nedergaard M, Ransom B, Goldman SA. New roles for astrocytes: Redefining the functional architecture of the brain. Trends Neurosci 2003 ; 26: 523-30.

[24] Iadecola C, Nedergaard M. Glial regulation of the cerebral microvasculature. Nat Neurosci 2007; 10: 1369-76.

[25] Bouzier-Sore AK, Serres S, Canioni P, Merle M. Lactate involvement in neuron-glia metabolic interaction: (13)C-NMR spectroscopy contribution. Biochimie 2003; 85: 841-48.

[26] Pellerin L, Bouzier-Sore AK, Aubert A, et al. Activity-dependent regulation of energy metabolism by astrocytes: an update. Glia 2007; 55: 1251-62.

[27] Desagher S, Glowinski J, Premont J. Astrocytes protect neurons from hydrogen peroxide toxicity. J Neurosci 1996; 16: 2553-62.

[28] Liddell JR, Hoepken HH, Crack PJ, Robinson SR, Dringen R. Glutathione peroxidase 1 and glutathione are required to protect mouse astrocytes from iron-mediated hydrogen peroxide toxicity. $\mathbf{J}$ Neurosci Res 2006; 84: 578-86.

[29] Lindon JC, Nicholson JK, Holmes E, Everett JR. Metabonomics: metabolic processes studied by NMR spectroscopy of biofluids. Conc Magn Reson 2000; 12: 289-320.

[30] Lindon JC, Holmes E, Nicholson JK. Toxicological applications of magnetic resonance. Prog Nucl Magn Reson 2004; 45: 109-43.

[31] Alves PM, Flogel U, Brand A, et al. Immobilization of primary astrocytes and neurons for online monitoring of biochemical processes by NMR. Dev Neurosci 1996; 18: 478-83.

[32] Nissen J, Olesen BT, Clausen J, Hansen PE. ${ }^{1}$ H NMR Studies of metabolic effects of endo-and exogeneous compound on astroglia cells cultivated in vitro. Open Magn Reson J 2008; 1: 88-94.

[33] Olesen BT, Clausen J, Vang O. Characterization of the transcriptional profile in primary astrocytes after oxidative stress induced by Paraquat. Neurotoxicology 2008; 29: 13-21.

[34] Hertz L, Juurlink BHJ, Fosmark H, Schousboe A. Preparation of primary cultures of mouse (rat) astrocytes. In: Shahar A, De Vellis J, Vernadakis A, Haber B, Eds. Dissection and tissue culture manual for neurons systems. New York: Alan R Liss; 1989: pp. 105-08.

[35] Eng LF, Vanderhaeghen JJ, Bignami A, Gerstl B. An acidic protein isolated from fibrous astrocytes. Brain Res 1971; 28: 351-4.

[36] Urenjak J, Williams SR, Gadian DG, Noble M. Proton nuclear magnetic resonance spectroscopy unambiguously identifies different neural cell types. J Neurosci 1993; 13: 981-9.

[37] Fan TW. Metabolite profiling by one- and two-dimensional NMR analysis of complex mixtures. Prog Nucl Magn Reson 1996; 28: 161-219.

[38] Isobe I, Yanagisawa K, Michikawa M. A possible model of senile plaques using synthetic amyloid beta-protein and rat glial culture. Exp Neurol 2000; 162: 51-60.
[39] Piotto M, Saudek V, Sklenar V. Gradient-tailored excitation for single-quantum NMR spectroscopy of aqueous solutions. J Biomol NMR 1992; 2: 661-5.

[40] Hahn EL. Spin echoes. Phys Rev 1950; 80: 580-94.

[41] Sklenar V, Piotto M, Leppik R, Saudek V. Gradient-tailored water suppression for $\mathrm{H}-1-\mathrm{N}-15 \mathrm{Hsqc}$ experiments optimized to retain full sensitivity. J Magn Reson A 1993; 102: 241-5.

[42] Sze DY, Jardetzky O. Determination of metabolite and nucleotide concentrations in proliferating lymphocytes by $1 \mathrm{H}-\mathrm{NMR}$ of acid extracts. Biochim Biophys Acta 1990; 1054: 181-97.

[43] Nicholson JK, Foxall PJ, Spraul M, Farrant RD, Lindon JC. 750 $\mathrm{MHz} 1 \mathrm{H}$ and $1 \mathrm{H}-13 \mathrm{C}$ NMR spectroscopy of human blood plasma. Anal Chem 1995; 67: 793-811.

[44] Petroff OA, Pleban LA, Spencer DD. Symbiosis between in vivo and in vitro NMR spectroscopy: the creatine, $\mathrm{N}$-acetylaspartate, glutamate, and GABA content of the epileptic human brain. Magn Reson Imaging 1995; 13: 1197-211.

[45] van Cappellen van Walsum AM, Jongsma HW, et al. Hypoxia in fetal lambs: a study with (1)H-MNR spectroscopy of cerebrospinal fluid. Pediatr Res 2001; 49: 698-704.

[46] Waagepetersen HS, Qu H, Hertz L, Sonnewald U, Schousboe A. Demonstration of pyruvate recycling in primary cultures of neocortical astrocytes but not in neurons. Neurochem Res 2002; 27: 143137.

[47] Fedotcheva NI, Sokolov AP, Kondrashova MN. Nonezymatic formation of succinate in mitochondria under oxidative stress. Free Radic Biol Med 2006; 41: 56-64.

[48] Tretter L, Adam-Vizi V. Inhibition of Krebs cycle enzymes by hydrogen peroxide: A key role of [alpha]-ketoglutarate dehydrogenase in limiting NADH production under oxidative stress. J Neurosci 2000; 20: 8972-79.

[49] Shi Q, Xu H, Kleinman WA, Gibson GE. Novel functions of the alpha-ketoglutarate dehydrogenase complex may mediate diverse oxidant-induced changes in mitochondrial enzymes associated with Alzheimer's disease. Biochim Biophys Acta 2008; 1782: 229-38.

[50] Desagher S, Glowinski J, Premont J. Pyruvate protects neurons against hydrogen peroxide-induced toxicity. J Neurosci 1997; 17: 9060-7.

[51] Parkes HG, Grootveld MC, Henderson EB, Farrell A, Blake DR. Oxidative damage to synovial fluid from the inflamed rheumatoid joint detected by 1H NMR spectroscopy. J Pharm Biomed Anal 1991; 9: 75-82

[52] Schiller J, Arnhold J, Schwinn J, Sprinz H, Brede O, Arnold K. Reactivity of cartilage and selected carbohydrates with hydroxyl radicals: an NMR study to detect degradation products. Free Radic Res 1998; 28: 215-28.

[53] Kotitschke K, Jung H, Nekolla S, Haase A, Bauer A, Bogdahn U. High-resolution one- and two-dimensional 1H MRS of human brain tumor and normal glial cells. NMR Biomed 1994; 7: 111-20.

[54] Kotitschke K, Schnackerz KD, Dringen R, Bogdahn U, Haase A, von Kienlin M. Investigation of the 1H NMR visibility of lactate in different rat and human brain cells. NMR Biomed 1994; 7: 349-55.

[55] Rodrigues TB, Cerdan S. A fast and sensitive 1H NMR method to measure the turnover of the $\mathrm{H} 2$ hydrogen of lactate. Magn Reson Med 2005; 54: 1014-9.

[56] Reglinski J, Smith WE, Suckling CJ, Al Kabban M, Stewart MJ, Watson ID. Doxorubicin-induced altered glycolytic patterns in the leukemic cell studied by proton spin echo NMR. Clin Chim Acta 1988; 175: 285-9.

[57] Dienel GA, Hertz L. Glucose and lactate metabolism during brain activation. J Neurosci Res 2001; 66: 824-38.

[58] Waagepetersen HS, Sonnewald U, Larsson OM, Schousboe A. A possible role of alanine for ammonia transfer between astrocytes and glutamatergic neurons. J Neurochem 2000; 75: 471-9.

[59] Bouzier-Sore AK, Voisin P, Canioni P, Magistretti PJ, Pellerin L. Lactate is a preferential oxidative energy substrate over glucose for neurons in culture. J Cereb Blood Flow Metab 2003; 23: 1298-306. 
[60] Serres S, Bouyer JJ, Bezancon E, Canioni P, Merle M. Involvement of brain lactate in neuronal metabolism. NMR Biomed 2003; 16: 430-9.

[61] Serres S, Bezancon E, Franconi JM, Merle M. Ex vivo NMR study of lactate metabolism in rat brain under various depressed states. J Neurosci Res 2005; 79: 19-25.

[62] Marrif H, Juurlink BHJ. Astrocytes respond to hypoxia by increasing glycolytic capacity. J Neurosci Res 1999; 57: 255-60.
[63]

Alves PM, Fonseca LL, Peixoto CC, Almeida AC, Carrondo MJ, Santos H. NMR studies on energy metabolism of immobilized primary neurons and astrocytes during hypoxia, ischemia and hypoglycemia. NMR Biomed 2000; 13: 438-48.

[64] Golman K, in't Zandt R, Thaning M, Real-time metabolic imaging. Proc Nat Acad Sci USA 2006; 103: 11270-5.

Received: January 19, 2009

Revised: November 23, 2009

Accepted: November 30, 2009

(c) Olesen et al.; Licensee Bentham Open.

This is an open access article licensed under the terms of the Creative Commons Attribution Non-Commercial License (http://creativecommons.org/licenses/by-nc/3.0/) which permits unrestricted, non-commercial use, distribution and reproduction in any medium, provided the work is properly cited. 